\title{
Manajemen Kegiatan Ekstrakurikuler Dalam Meningkatkan Prestasi Non Akademik Siswa
}

\author{
Ayu Sundari \\ ${ }^{1}$ Pascasarjana Institut Pesantren KH. Abdul Chalim Pacet Mojokerto, Indonesia \\ e-mail: ayuusundarii@gmail.com
}

Submitted: 05-01-2021 Revised : 15-03-2021 Accepted: 14-04-2021

\begin{abstract}
ABSTRAK. Kegiatan ekstrakurikuler merupakan wadah bagi siswa yang memiliki minat dan bakat. Kegiatan ekstrakurikuler dapat membantu mengembangkan potensi diri dalam meningkatkan prestasi peserta didik. Prestasi siswa tidak hanya didapat dari prestasi akademiknya saja, dengan pretasi non akademik siswa dapat mampu berkokunikasi dan bersosialisasi dengan baik. Dengan adanya manajemen eksrakurikuler yang baik maka akan menghasilkan prestasi didalam bidang non akademik. Madrasah Aliyah Negeri 1 Mojokerto merupakan salah satu Madrasah yang telah banyak melahirkan siswa dengan prestasi non akademik. Hasil penelitian ini adalah (1) manajemen kegiatan ekstrakurikuler di Madrasah Aliyah Negeri 1 Mojokerto meliputi, pertama perencanaan kegiatan ekstrakurikuler dilaksanakan setiap awal tahun ajaran baru, kedua pengorganisasian dilakukan oleh para guru pembina ekstrakurikuler dengan cara pemberian tugas bagi pembina yang mempunyai kompetensi dibidangnya. Ketiga pelaksanaan kegiatan ekstrakurikuler dilakukan setiap hari sesuai dengan jadwal yang telah ditetapkan, keempat pengawasan dilakukan dengan adanya presensi kehadihan guru pembina dan siswa. (2) prestasi non akademik siswa setelah diadakannya manajemen kegiatan ekstrakurikuler sudah baik dan semakin meningkat. Dilihat dari proses pendidikannya yang berjalan dengan baik dan lancar, adanya manajemen estrakurikuler yang baik Madrasah Aliyah Negeri 1 Mojokerto dapat meraih prestasi, baik yang dilaksanakan dalam tingkat Kabupaten maupun Provinsi.

Kata Kunci: Manajemen, Ekstrakurikuler, Prestasi Non-Akademik.

Abstract: Extracurricular activities are a place for students who have interests and talents. Extracurricular activities can help develop self-potential in increasing student achievement. Student achievement is not only obtained from academic achievement, with non-academic achievements students can be able to communicate and socialize well. With good extracurricular management it will result in achievements in non-academic fields. Madrasah Aliyah Negeri 1 Mojokerto is one of the madrasas that has produced many students with non-academic achievements. The results of this study are (1) the management of extracurricular activities at Madrasah Aliyah Negeri 1 Mojokerto includes, first planning for extracurricular activities carried out at the beginning of the new academic year, secondly organizing is carried out by extracurricular guidance teachers by assigning assignments to coaches who have competence in their fields. The third implementation of extracurricular activities is carried out every day according to a predetermined schedule, the fourth supervision is carried out with the presence of the supervisor and students. (2) students' non-academic achievement after the management of extracurricular activities is good and is increasing. Judging from the educational process that went well and smoothly, the existence of good estracurricular management at Madrasah Aliyah Negeri 1 Mojokerto was able to achieve achievements, both at the district and provincial levels.
\end{abstract}

Keywords: Management, Extracurricular, Non-Academic Achievements. 
https://dx.doi.org

How to Cite Sundari, A. (2021). Manajemen Kegiatan Ekstrakurikuler Dalam Meningkatkan Prestasi Non Akademik Siswa. Munaddhomah: Jurnal Manajemen Pendidikan Islam, 2(2), 1-8

\section{PENDAHULUAN}

Pendidikan merupakan peran penting dalam meningkatkan kualitas sumber daya manusia. Melalui pendidikan manusia menjadi cerdas, memiliki skill, sikap hidup yang baik sehingga dapat bergaul dengan baik di masyarakat dan dapat menolong dirinya sendiri, keluarga, dan masyarakat (Muslimin \& Kartiko, 2020; Tajudin \& Aprilianto, 2020). Pendidikan menjadi investasi yang memberi keuntungan sosial dan pribadi yang menjadikan bangsa bermartabat dan menjadikan individualnya manusia yang memiliki derajat (Engkoswara, 2004, p. 77)

Dalam proses pendidikan dikenal dua kegiatan yang cukup elementer, yaitu kegiatan kurikuler dan kegiatan ekstrakurikuler (Oktadiana Et Al., 2019; Sj Et Al., 2021). Pertama, kurikuler erupakan kegiatan pokok pendidikan yang didalamnya terjadi proses belajar mengajar antara peserta didik dan guru untuk mendalami materi-materi pengetahuan yang berkaitan dengan tujuan pendidikan dan kemampuan yang hendak diperoleh peserta didik (Matwaya \& Zahro, 2020; Rofi'ah, 2020). Kedua, ekstrakurikuler merupakan kegiatan yang dilakukan dalam rangka mengembangkan aspek-aspek tertentu dari apa yang ditemukan pada kurikulum yang sedang dijalankan, termasuk yang berhubungan dengan bagaimana penerapan sesungguhnya dari ilmu pengetahuan yang dipelajari oleh peserta didik sesuai dengan tuntunan kebutuhan hidup mereka maupun lingkungan sekitarnya. (Mulyono, 2009, pp. 185-186). Pemendikbud RI Nomor 81 tahun 2013 tentang implementasi kurikulum Pedoman Kegiatan Ekstrakurikuler, disebutkan bahwa didalam kurikulum 2013. kegiatan ekstrakurikuler dibedakan menjadi kegiatan ektrakurikuler wajib dan kegiatan ekstrakurikuler pilihan.

Kualitas kegiatan ekstrakurikuler di suatu lembaga pendidikan menjadi salah satu indikator kualitas pendidikan didalamnya secara menyeluruh. Ekstrakurikuler seakan menjadi brand image bagi sekolah/madrasah yang akan meningkatkan bargaining price kepada calon peminatnya. Bahkan, dalam sekolah-sekolah unggulan ekstrakurikuler mendapatkan prioritas utama dalam rangka mengangkat prestige sekolah yang dikelolanya (Pakpahan \& Habibah, 2021). Adanya persaingan yang ketat di bidang ekstrakurikuler yang terjadi di dunia pendidikan belakangan ini menjadi bukti bahwa sekolah harus berusaha keras agar sekolah mampu mengelola kegiatan pendidikan secara baik dan bermutu tinggi. Pengelola lembaga pendidikan diharapkan mampu mengantarkan anak didiknya menjadi siswa berprestasi di banyak bidang dalam ajang lomba yang diadakan untuk tingkat para pelajar, baik secara akademik maupun non akademik. Sekolah yang mampu menjadi juara, dialah yang akan mendapatkan kepercayaan lebih banyak dari masyarakatnya (Astuti, 2016, p. 3)

Menurut Mulyono, Manajemen ekstrakurikuler merupaka pengelolaan kegiatan ekstrakurikuler meliputi seluruh proses yang direncanakan dan diusahakan secara terorganisasi mengenai kegiatan sekolah yang dilakukan diluar kelas dan diluar jam pelajaran (kurikulum) untuk menumbuh kembangkan potensi SDM yang dimiliki peserta didik, baik berkaitan dengan aplikasi ilmu pengetahuan yang didapatkannya maupun dalam pengertian khusus untuk membimbing peserta didik dalam mengembangkan potensi dan bakat yang ada dalam dirinya melalui kegiatankegiatan yang wajib maupun pilihan. (Kompri, 2015, p. 238). Keberhasilan Manajemen Ekstrakurikuler tersebut akan menghasilkan prestasi dalam bidang non akademik. (Mulyono, 2009, p. 188) juga mengatakan bahwa prestasi non akademik adalah prestasi atau kemampuan yang dicapai peserta didik di luar jam kurikuler atau dapat disebut kegiatan ekstrakurikuler. 
Dalam Penelitian ini Madrasah Aliyah Negeri 1 Mojokerto adalah sekolah yang telah menerapkan manajemen kegiatan ektrakurikuler. Untuk meningkatkan prestasi siswa di Madrasah Aliyah Negeri 1 Mojokerto perlu adanya dukungan yang kuat dalam kegiatan pembelajaran, penggunaan sarana prasarana pendidikan sesuai dengan ketentuan standar nasional pendidikan Keberadaan kegiatan ekstrakurikuler merupakan wadah perkumpulan peserta didik berdasarkan minat, bakat, dan kecenderungannya untuk beraktivitas dan berkreativitas di luar program kurikuler. Kegiatan ekstrakurikuler bertujuan untuk mengembangkan salah satu bidang pelajaran yang diminati oleh sekelompok peserta didik misalnya, olahraga, kesenian, berbagai macam, keterampilan, kepramukaan, dan sebagainya (Syafaruddin, 2005, p. 265)

Berbagai kendala juga masih dihadapi yaitu banyaknya ekstrakurikuler yang ada dan waktu jam pelajaran kurikuler yang panjaang sering kali menjadi kesulitan tersendiri dalam mengatur waktu dan jadwal kegiatan ekstrakurikuler. Siswa juga sering kali tidak maksimal mengikuti kegiatan ekstrakurikuler tersebut karna merasa lelah setelah jam pelajaran yg panjang, bukan hanya siswa Pembina kegiatan ekstrakurikuler juga mengalami kesulitan yaitu kurang maksimal dalam memberikan materi-materi kegiatan karna jam ekstrakurikuler yang lumayan singkat. Dan yang penting juga kendala tersebut adalah penyediaan fasilitas, kegiatan lomba dan lainya tentunya membutuhkan banyak biaya, dari masalah dan kendala yang ada banyak potensi, bakat, dan kemampuan siswa yang tidak teralurkan dengan baik.

\section{METODE PENELITIAN}

Penelitian ini menggunakan penelitian kualitatif, adapun pendekatan dalam penelitian ini adalah studi kasus. Studi kasus cenderung meneliti jumlah unit yang kecil tetapi mengenai variabel variabel yang kondisi yang jumlahnya besar. Studi kasus bersifat intersif, menerangi variabelvariabel yang penting, proses-proses dan interaksi yang memerlukan perhatian luas. Sementara data yang diperoleh dari studi kasus memberikan contoh-contoh yang berguna mengenai penemua-penemuan yang digeneralisasikan dengan statistic. (Djam'an Satori, 2013, p. 22) Pengumpulan data dilakukan dengan observasi, wawancara, dokumentasi. Pemeriksaan keabsahan data menggunakan terknik triangulasi data. Analisis data dilakukan dengan model interaktif yang terdiri atas reduksi data, penyajian data dan kesimpulan.

\section{HASIL DAN PEMBAHASAN}

\section{Manajemen Ekstrakurikuler}

Manajemen Ekstrakurikuler Menurut Mulyono dalam (Kompri, 2015, p. 238) adalah seluruh proses yang direncanakan dan diusahakan secara terorganisasi mengenai kegiatan sekolah yang dilakukan diluar kelas dan diluar jam pelajaran (kurikulum). Konsep manajemen dalam Islam menjelaskan bahwa setiap manusia hendaknya memperhatikan apa yang telah diperbuat pada masa yang telah lalu untuk merencanakan hari esok. Seperti yang dijelaskan di dalam QS. Al-Hasyr 59: 18.

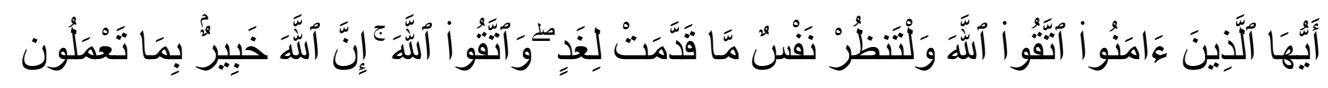

Artinya: 
"Hai orang-orang yang beriman, bertakwalah kepada Allab dan bendaklah Setiap diri memperbatikan apa yang telah diperbuatnya untuk hari esok (akbirat); dan bertakwalah kepada Allah, Sesunggubnya Allab Maha mengetabui apa yang kamu kerjakan.”

Kegiatan ekstrakurikuler pada dasarnya diberikan/disediakan untuk semua siswa sesuai dengan potensi, minat, bakat, dan kemampuannya. Kegiatan ekstrakurikuler pada prinsipnya didasarkan pada kebijakan yang berlaku dan kemampuan sekolah, kemampuan para orang tua/masyarakat, dan kondisi lingkungan sekolah.

Dengan adanya kegiatan ekstrakurikuler ini dapat mencegah siswa untuk melakukan tindakan yang menjurus kepada hal-hal yang negatif, seperti ketika pulang sekolah atau pada waktu liburan, peserta didik dapat menghabiskan waktunya di sekolah bersama dengan kelompok teman sebayanya dalam melakukan kegiatan yang bermanfaat yang dibimbing oleh guru pembina ekstrakurikuler. Mereka dapat melakukan kegiatankegiatan positif menyangkut kegiatan ekstrakurikuler di sekolah. Kegiatan ekstrakurikuler ini dapat dijadikan sebagai alat untuk memotivasi peserta didik untuk memperbaiki dan mengembangkan potensi yang ada pada dirinya. Peserta didik dapat mengaplikasikan nikmat-nikmat yang telah diberikan Allah SWT kepadanya dengan cara melatih dirinya melalui kegiatan ekstrakurikuler.

Seperti firman Allah SWT dalam QS. Al-Anfal ayat 53, yakni :

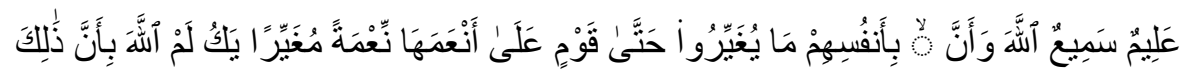

Artinya :

"(siksaan) yang demikian itu adalah karena Sesunggubnya Allah sekali-kali tidak akan meubah sesuatu nikmat yang telah dianugerabkan-Nya kepada suatu kaum, bingga kaum itu meubah apa-apa yang ada pada diri mereka sendiri dan Sesunggubnya Allab Maha mendengar lagi Maha mengetabui.Allah tidak mencabut nikmat yang telab dilimpabkan-Nya kepada sesuatu kaum, selama kaum itu tetap taat dan bersyukur kepada Allah."

Manajemen Ektrakurikuler dalam hal ini memiliki fungsi sebagai serangkaian kegiatan-kegiatan dalam sebuah organisasi yang dilakukan oleh seorang manajer dalam mengelola organisasi. Sedangkan manajemen atau pengelolaan mempunyai fungsi kegiatan yaitu, Perencanaan (planning), Pengorganisasian (Organizing), Penggerakkan (Actuating), Pengendalian (Controlling). (Doni, 2018, pp. 22-24).

\section{Perencanaan}

Perencanaan dapat didefinisikan sebagai penentuan terlebih dahulu hal-hal yang harus dikerjakan, kapan dikerjakan, dan siapa yang mengerjakannya. dalam perencanaan terlibat unsur penentuan yang berarti bahwa dalam perencanaan tersebut tersirat pengambil keputusan (Hafied, 2014; Hamalik, 2003; Ikhwan, 2016).

Berdasarkan temuan yang diperoleh dari hasil wawanvara dari beberapa sumber Perencanaan kegiatan ekstrakurikuler di Madrasah Aliyah Negeri 1 Mojokerto dilakukan setiap awal tahun ajaran baru. Perencanaan dilakukan melalui rapat 
koordinasi. Hal-hal yang direncanakan meliputi peserta kegiatan ekstrakurikuler, perekrutan guru pembina, jadwal kegiatan, penyedian sarana prasaran, dana kegiatan.

\section{Pengorganisasian}

Tujuan pengorganisasian adalah untuk mengekelompokan kegiatan sumber daya manusia dan sumber daya lainnya yang dimiliki agar pelaksanaan dari suatu rencana dapat dicapai secara efektif dan ekonomis. Langkah pertama yang sangat penting dalam pengorganisasian, yang umumnya harus dilakukan setelah perencanaan adalah proses mendesain organisasi, yaitu penentuan struktur organisasi yang paling memadai untuk strategi, orang, teknologi, dan tugas organisasi(Warti'ah, 2020).

Berdasarkan temuan yang diperoleh dari hasil wawanvara pengorganisasian kegiatan ekstrakurikuler di Madrasah Aliyah Negeri 1 Mojokerto telah dilakukan dengan baik oleh kepala sekolah dan waka kesiswaan, yaitu dengan pembagian tugas untuk pembinaan ekstrakurikuler yang telah disesuaikan dengan bidang dan keahliannya masing-masing. Pengorganisasian tersebut dilaksanakan dengan tujuan agar kegiatan ekstrakurikuler tersebut dapat berjalan secara maksimal dan tercapai tujuan yang maksimal dalam meningkatkan prestasi non akademik siswa.

\section{Pelaksanaan}

Pelaksanaan akan dilakukan oleh pemimpin untuk memberikan penjelasan, petunjuk serta bimbingan kepada bawahannya sebelum dan selama melaksanakan tugas. Kepemimpinan merupakan suatu proses untuk mempengaruhi aktivitas kelompok yang terorganisasi dalam usaha pencapaian tujuan telah ditetapkan. Memimpin merupakan proses mempengaruhi yang lain untuk bekerja menuju pencapaian tujuan tertentu (Rony, 2021).

Berdasarkan temuan yang diperoleh dari hasil wawanvara kegiatan ekstrakurikuler yang dilaksanakan di Madrasah Aliyah Negeri 1 Mojokerto merupakan bentuk pembinaan atau pelatihan terhadap siswa. Kegiatan ekstrakurikuler merupakan kegiatan membina siswa dalam bisang non akademik. Tujuannya untuk mengusahakan agar siswa tumbuh dan berkembang menjadi manusia yang berkualitas sesuai dengan tujuan pendidikan, melalui pengembangan segala potensi yang dimiliki siswa.

\section{Pengawasan}

Pengawasan adalah suatu upaya yang sistematis untuk menetapkan standar prestasi dengan sasaran perencanaan perancang sistem umpan balik informasi sesungguhnya dengan penetapan standar terlebih dahulu, menentukan apakah ada penyimpangan dan mengukur signifikasi penyimpangan tersebut, serta mengambil tindakan perbaikan yang diperlukan untuk menjamin secara optimal sumber daya organisasi yang digunakan dengan cara yang paling efektif dan efisien agar tercapainya sasaran organisasi. Jadi, tujuan utama dari pengendalian adalah memastikan bahwa hasil kegiatan sesuai dengan yang telah direncanakan (Hakim, 2016; Kartiko \& Azzukhrufi, 2019). 
Berdasarkan temuan yang diperoleh dari hasil wawanvara kegiatan pengawasan ekstrakurikuler di Madrasah Aliyah Negeri 1 Mojokerto pada dasarmya membandingkan kondisi yang ada dengan yang seharunya terjadi. Apabila dalam prosesnya terjadi penyimpangan/hambatan/penyelewengan segera dilakukan tindakan koreksi.

\section{Prestasi Non Akademik Siswa}

Menurut (Umiarso, 2010, p. 226) , menyatakan bahwa prestasi adalah hasil penilaian pendidikan atas perkembangan dan kemajuan siswa dalam belajar. Prestasi menunjukkan hasil dari pelaksanaan kegiatan yang diikuti siswa di sekolah. Menurut (Mulyono, 2009, p. 188) mengatakan bahwa prestasi non akademik adalah prestasi atau kemampuan yang dicapai peserta didik di luar jam kurikuler atau dapat disebut kegiatan ekstrakurikuler. Dalam prespektif islam diungkapkan pada Hadist Hasan yang diriwayatkan oleh imam tirmidzi, dari Anas r.a : Rasulullah SAW bersabda:

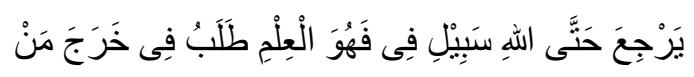

Artinya :

"barangsiapa keluar untuk menuntut ilmu, maka ia dianggap sebagai orang yang berjihad fi sabilillah sehingga ia kembali"

Prestasi dalam bahasa kehidupan sering ditandai dengan pencapaian status atau kondisi yang lebih baik atau setidak-tidaknya prestasi adalah jika seseorang tetap mampu mempertahankan status dan keadaan yang sudah dicapai. Tolak ukur prestasi bisa dengan membandingkan diri sendiri, orang lain, lembaga atau organisasi lain terhadap tingkat pencapainya. Bahkan dalam rangka mengejar prestasi tersebut dalam realitasnya banyak manusia yang menempuh jalan dengan menerobos rambu-rambu yang telah digariskan dalam syariah islam.

Prestasi yang hakiki dalam pandangan Islam adalah tidak hanya pada puncak pencapian kesuksesan saja, tetapi juga diniatkan, diproses dan didapatkan sesuai dengan akidah Islam sebab dalam konsep Islam setiap amal perbuatan pasti dicatat dan kelak akan dimintai pertanggung jawabanya dan Allah akan memberikan pahala atas segala usahanya dan kerja kerasnya.

Berdasarkan temuan yang diperoleh dari hasil wawanvara Adapun prestasi non akademik setelah diadakanya manajemen kegiatan ekstrakurikuler di dalam yang ada di Madrasah Aliyah Negeri 1 Mojokerto tergolong baik dan semakin meningkat. Dilihat dari proses pendidikannya yang berjalan dengan lancar dan adanya sarana prasaran pendukung .Jika dilihat dari hasil pencapaianya juga tergolong sangat baik, dapat dilihat dari banyaknya prestasi yang telah diraih oleh siswa dalam setiap perlombaan- perlombaan. Baik yang dilaksanakan dalam tingkat Kabupaten maupun Provinsi.

Dengan adanya manajemen ekstrakurikuler yang baik, maka Madrasah Aliyah Negeri 1 Mojokerto dapat meraih prestasi dibidang non akademik. Prestasi non akademik yang pernah diraih oleh siswa Madrasah Aliyah Negeri 1 Mojokerto antara lain: 
juara I lomba PBB Provinsi Jawa Timur 2018, juara II senam Pramuka Provinsi Jawa timur 2018, juara I kejuaran karate antar pelajar Provinsi Jawa Timur 2018.

\section{KESIMPULAN}

Manajemen Ekstrakurikuler Dalam Meningkatkan Prestasi Non Akademik Siswa Di MAN 1 Mojokerto ini berjalan dengan baik karena adanya (1) perencanaan yang dilakukan dengan baik seperti mengadakan rapat menentukan peserta kegiatan, perekrutan guru pembina, menentukan jadwal kegiatan, menentukan sarana prasara pendukung kegiatan, menentukan pendanaan kegiatan. Kemudian adanya (2) pengorganisasian yang mempermudah untuk menentukan tugas dari masing-masing pembina kegiatan, pihak-pihak yang terlibat dalam struktur organisasi tersebut, kepala sekolah, waka kurikulum, waka kesiswaan, guru pembina. (3) Pelaksanaan kegiatan ekstrakurikuler merupakan bentuk pembinaan atau pelatihan terhadap siswa. Kegiatan ekstrakurikuler merupakan kegiatan membina siswa dalam bisang non akademik. Tujuannya untuk mengusahakan agar siswa tumbuh dan berkembang menjadi manusia yang berkualitas sesuai dengan tujuan pendidikan, melalui pengembangan segala potensi yang dimiliki siswa. (4) pengawasan kegiatan ekstrakurikuler dilakukan oleh waka kesiswaan dan guru pembina pengawasan pada dasarmya membandingkan kondisi yang ada dengan yang seharunya terjadi. Apabila dalam prosesnya terjadi penyimpangan/ hambatan/ penyelewengan segera dilakukan tindakan koreksi.

Prestrasi non akademik siswa setelah diadakan manajemen ektrakurikuler di Madrasah Aliyah Negeri 1 Mojokerto sudah baik dan semakin meningkat. Dilihat dari proses pendidikannya yang berjalan dengan lancar dan adanya sarana dan prasarana pendukung. Dengan adanya manajemen ekstrakurikuler yang baik, maka Madrasah Aliyah Negeri 1 Mojokerto dapat meraih prestasi dibidang non akademik. Prestasi non akademik yang pernah diraih oleh siswa Madrasah Aliyah Negeri 1 Mojokerto antara lain : juara I lomba PBB Provinsi Jawa Timur 2018, juara II senam Pramuka Provinsi Jawa timur 2018, juara I kejuaran karate antar pelajar Provinsi Jawa Timur 2018.

\section{REFERENSI}

Astuti, T. (2016). pelaksanaan manajemen mutu kegiatan ekstrakurikuler di SMK Negeri 1 Purwokerto. 3.

Djam'an Satori, \&. d. (2013). Metode penelitian Kualitatif. Bandung: Alfabeta.

Doni, J. P. (2018). Manajemen \& Supervisi Pendidikan. Bandung: CV Pustaka Setia.

Engkoswara, d. A. (2004). administrasi pendidikan. Bandung: PT Remaja Rosdakarya.

Kompri. (2015). Manajemen Pendidikan. Yogyakarta: Az Ruzz Media.

Mulyono. (2009). Manajemen Administrasi dan organisasi pendidikan. Yogyakarta: Az-Ruzz Media.

Syafaruddin. (2005). Manajemen Lembaga Pendidikan islam. Jakarta: Ciputat Press.

Umiarso, \&. I. (2010). Manajemen Mutu Sekolah di Era Otonomi Pendidikan . Yogyakarta: IRCiSoD.

Hafied, C. (2014). Perencanaan Dan Strategi Komunikasi. Raja Grafindo Persada.

Hakim, M. N. (2016). Implementasi Manajemen Berbasis Sekolah Dalam Mewujudkan Sekolah Islam Unggulan. Nidhomul Haq: Jurnal Manajemen Pendidikan Islam, 1(2), 104-114. https://doi.org/10.31538/ndh.v1i2.7

Hamalik, O. (2003). Perencanaan pengajaran berdasarkan pendekatan sistem. Bumi Aksara.

Ikhwan, A. (2016). Manajemen Perencanaan Pendidikan Islam (kajian Tematik Al-Qurâ $€^{\mathrm{TM}}$ an Dan Hadist). Edukasi: Jurnal Pendidikan Islam, 4(1), 128-155. http://ejournal.staimtulungagung.ac.id/index.php/EDUKASI/article/view/194 
Kartiko, A., \& Azzukhrufi, jaya R. (2019). Pengaruh Budaya Organisasi Dan Kompensasi Terhadap Kinerja Pendidik Di Madrasah Aliyah Nahdlatul Ulama Mazro'atul Ulum Paciran. Nidhomul Haq: Jurnal Manajemen Pendidikan Islam, 4(2), 207-226. https://doi.org/10.31538/ndh.v4i2.351

Matwaya, A. M., \& Zahro, A. (2020). Konsep Spiritual Quotient Menurut Danah Zohar dan Ian Marshall Dalam Perspektif Pendidikan Islam. Attadrib: Jurnal Pendidikan Guru Madrasah Ibtidaiyah, $3(2)$ $41-48$. http://www.jurnal.staidagresik.ac.id/index.php/attadrib/article/view/112

Muslimin, T. A., \& Kartiko, A. (2020). Pengaruh Sarana dan Prasarana Terhadap Mutu Pendidikan di Madrasah Bertaraf Internasional Nurul Ummah Pacet Mojokerto. Munaddhomah: Jurnal Manajemen Pendidikan Islam, 1(2), 75-87. https://pasca.jurnalikhac.ac.id/index.php/munaddhomah/article/view/30

Oktadiana, B., Hayati, E., \& Sofiana, I. A. (2019). Analisis Perkembangan Bahasa Anak Usia Dasar (Tercapai) Di MI Ma’arif Sambego. Ną̧hruna: Jurnal Pendidikan Islam, 2(2), 225-245. https://doi.org/10.31538/nzh.v2i2.335

Pakpahan, P. L., \& Habibah, U. (2021). Manajemen Program Pengembangan Kurikulum PAI dan Budi Pekerti dalam Pembentukan Karakter Religius Siswa: Management of IRE Curriculum Development Program and Character in Forming Student's Religious Character. Tafkir: Interdisciplinary Journal of Islamic Education, 2(1), 1-20. https://doi.org/10.31538/tijie.v2i1.19

Rofi'ah. (2020). Meningkatkan Motivasi Belajar Pendidikan Sejarah Kebudayaaan Islam Melalui Metode Pembelajaran Mind Mapping. Attadrib: Jurnal Pendidikan Guru Madrasah Ibtidaiyah, 3(2), 33-40. http://www.jurnal.staidagresik.ac.id/index.php/attadrib/article/view/109

Rony. (2021). Urgensi Manajemen Budaya Organisasi Sekolah Terhadap Pembentukan Karakter Peserta Didik: The Urgency of School Organizational Culture Management Against Character Building Students. Tafkir: Interdisciplinary Journal of Islamic Education, 2(1), 98-121. https://doi.org/10.31538/tijie.v2i1.26

Sj, D. S., Maarif, M. A., \& Zamroni, A. (2021). Strategi Pengembangan Program Pembelajaran Pendidikan Agama Islam Sekolah: The Development Strategy of Islamic Religious Education Learning Programs. Tafkir: Interdisciplinary Journal of Islamic Education, 2(1), 20 40. https://doi.org/10.31538/tijie.v2i1.21

Tajudin, A., \& Aprilianto, A. (2020). Strategi Kepala Madrasah..dalam Membangun Budaya Religius Peserta Didik. Munaddhomah: Jurnal Manajemen Pendidikan Islam, 1(2), 101-110. https://pasca.jurnalikhac.ac.id/index.php/munaddhomah/article/view/34

Wartiah, W. (2020). The Implementation of Madrasa Culture in Building Students' Character. Nazhruna: Jurnal Pendidikan Islam, 3(2), 247-259. https://doi.org/10.31538/nzh.v3i2.583 